\title{
DETERMINATION OF STRUCTURE PARAMETERS OF POROUS SILICON BY THE PHOTOELECTRIC METHOD
}

\author{
D. F. Timokhov, F. P. Timokhov \\ Odessa National University, 2 Dvoryanska Str., Odessa, UA-65026, Ukraine
}

(Received April 22, 2003; received in final form October 24, 2003)

\begin{abstract}
Electrical and photoelectrical properties of $\mathrm{Al}$ /porous silicon/ monocrystalline silicon sandwichstructures $(\mathrm{Al} / \mathrm{PS}-(\mathrm{c}-\mathrm{Si}))$ based on nanostructured porous silicon, obtained by electrochemical anodization of monocrystalline silicon wafers are reported. The photosensitivity of $\mathrm{Al} / \mathrm{PS}-(\mathrm{c}-\mathrm{Si})$ structures is determined by PS layer photoconduction. The photoelectrical method of definition of effective band gap in the vicinity of PS-(c-Si) heterojunction is proposed. The opportunity of definition of the effective diameter of quantum wires is shown. Diffusion length of the minority charge carriers in porous silicon is determined by the method of reverse photocurrent.

Key words: porous silicon, photoelectric method, quantum wire

PACS number(s): 72.80.Cw; 72.80.Ng; 72.40.+w; 73.40.Gk
\end{abstract}

\section{INTRODUCTION}

The obtaining and researching of porous silicon (PS) as a new morphological form of monocrystalline silicon is of interest by virtue of unusual physical properties $[1,2]$. The basic differences of the given nanostructured material in relation to its monocrystalline prototype is shown in the shift of the fundamental absorption edge in the shortwave region and occurrence intensive electro- and photoluminescence in the visible spectral range [3-9]. Physical features of porous silicon are connected with quantum confinement effects, i. e., with a change of the band diagram and increase of effective band gap.

The photoelectric method of semiconductor structure property investigated is used for studying of the generation processes and recombination of charge carriers, current transport mechanisms, and also for clarifying the parameters of complex semiconductor structure band diagrams. In the presented paper the photoelectric method to study structural and electronic properties of porous silicon obtained by the method of electrochemical etching is applied.

\section{PREPARATION OF SAMPLES}

Porous silicon samples were prepared by electrochemical etching of Si substrates with [111] and [100] orientation and $10 \Omega \cdot \mathrm{cm}$ resistivity in HF-ethanol solution $\left(\mathrm{HF}(49 \%): \mathrm{C}_{2} \mathrm{H}_{5} \mathrm{OH}-1: 1\right)$. Anodization was carried out at the room temperature. Anodization current density was varying from 5 to $40 \mathrm{~mA} / \mathrm{cm}^{2}$. The time of etching changed from several minutes to one hour. The received samples were maintained in the open air during one week for stabilization of the created porous layers. The thickness of porous silicon layers was $0.2-60 \mu \mathrm{m}$. The PL spectra of the obtained PS samples were measured [8] using an UV nitrogen laser $(\lambda=337 \mathrm{~nm}$, pulse duration $\tau=10 \mathrm{~ns}$, frequency $f=50 \mathrm{~Hz}$, average power $3 \mathrm{~mW}$ ). After that PS samples were installed into the vacuum cham- ber. Aluminum films were evaporated onto the PS layers for preparation of the $\mathrm{Al} / \mathrm{PS} / \mathrm{c}-\mathrm{Si}$ sandwich-structures.

\section{RESULTS AND DISCUSSION}

Fig. 1 shows the energy band diagram of PS/c-Si heterojunction, which is received by the analysis of the capacitance-voltage characteristics, photocurrent spectra, current-voltage characteristics of photo- and dark conductivity and their temperature dependences. As it follows from the the analysis of capacitance-voltage characteristics for thin PS layers junction between PS layers and bulk $\mathrm{Si}$ is quasi-sharp. In the thick layers capacity weakly depends on the applied tension. The reason of capacity versus bias voltage dependence weak change in thick PS layers $(d>10 \mu \mathrm{m})$ can explain nonideal form of heterojunction between PS and bulk Si is and the formation of compensated transitive $\nu$-layer during anodic etching of silicon. Experimentally received data of structures capacities $(C)$ versus the PS layer thickness under the constant bias at a single frequency of $1 \mathrm{MHz}$ is in reasonable agreement with the calculated curve with taking into account that the capacity structure includes two series of capacity-geometrical capacity of a PS layer $\left(C_{\mathrm{ps}}\right)$ and capacity of a potential barrier on PS/c-Si heterojunction $\left(C_{\Gamma}\right)$.

In Fig. 2 the dependence of structures capacities on the porous layer thickness measured at constant reverse bias $-2 \mathrm{~V}$ are presented. Calculated values of $C, C_{\mathrm{ps}}$ and $C_{\Gamma}$ are shown there too. It was supposed that

$$
C_{\mathrm{ps}}=\frac{S \varepsilon_{\mathrm{ps}} \varepsilon_{0}}{d}, \quad C_{\Gamma}=\left[\frac{e \varepsilon_{\mathrm{Si}} \varepsilon_{0} N_{d}}{\left(V_{b}-V\right)}\right]^{1 / 2}
$$

here $\varepsilon_{\mathrm{PS}}$ and $\varepsilon_{\mathrm{Si}}$ are the permittivities of PS and bulk Si respectively, $\varepsilon_{0}$ is the permittivity of free space, $N_{d}$ the donor concentration, $V_{b}$ the band bending. We used 
the following values $S=4 \mathrm{~mm}^{2}, \varepsilon_{\mathrm{ps}}=1.6, \varepsilon_{\mathrm{Si}}=12$, $N_{d}=2 \cdot 10^{21} \mathrm{~m}^{-3}, V_{b}=0.35$ volt, $V=-2$ volts.

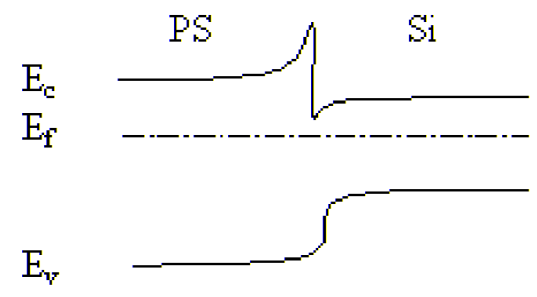

Fig. 1. Energy band diagram of PS/c-Si heterojunction.

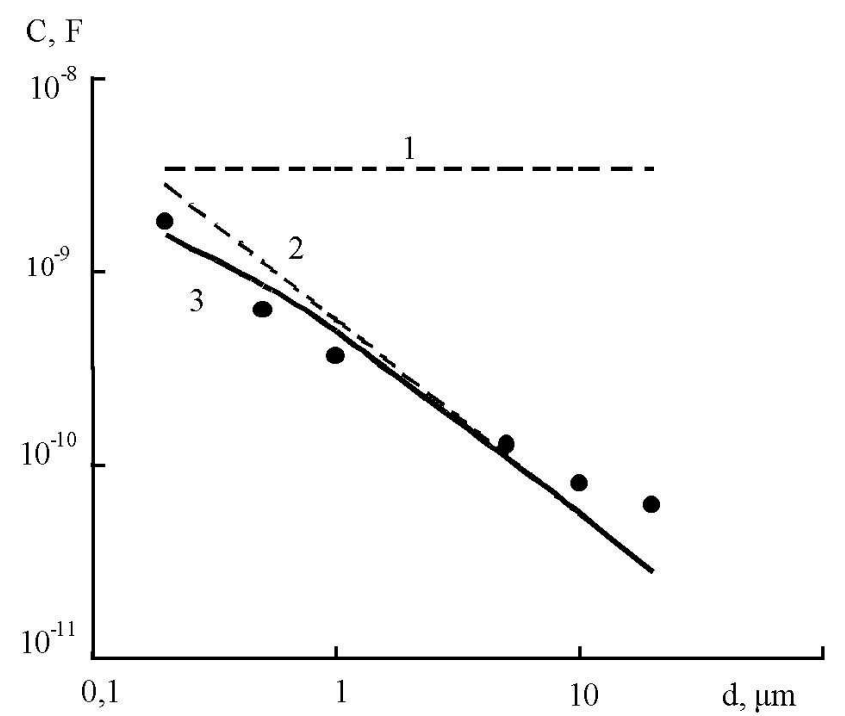

Fig. 2. AL/PS/c-Si structures capacities versus porous silicon layer thikness: 1 - barier capacity of heterojunction; 2 - geometrical capacity of porous silicon layer; 3 - capacity of heterojunction and porous silicon layer.

At construction of calculated dependences it was supposed that the major potential drop is produced on the heterojunction barrier because of its extremely high resistivity. We note a good agreement between the experimental result and the theoretical calculation. The agreement allows to make a conclusion that the current at the reverse bias will be limited to the resistance of this barrier. In such structures with a thin PS layer the dark current shows rectifying characteristics. The ratio of the forward current to the reverse current at low voltages achieves $\sim 10^{4}$. With increase of PS thickness ( $>10 \mathrm{mi}-$ crons) the rectifying on heterojunction decreases.

In some $\mathrm{Al} / \mathrm{PS} / \mathrm{c}-\mathrm{Si}$ sandwich structures on the direct branch of current-voltage characteristics a sharp increase of the current was observed. The decreasing of temperature results in the reduction of the breakdown voltage. Avalanche multiplication of photocurrent and recombination radiation take place at the achievement of the breakdown voltage, proving the generation of minority charge carriers.

The photocurrent spectra of the investigated samples, depending on the value and polarity of the bias voltage, have shown their complicated character. The sign inversion of photo-EMF is found out.

The definition of PS structure parameters is carried out by the photoelectric method. The analysis of photocurrent spectra has shown, that the PS band gap in the vicinity of PS/c-Si heterojunction can be determined by dependence of the short-circuit photocurrent of structure $I_{\mathrm{ph}}$ on photon energy $h \nu$, at a photon flux is incident on the PS in parallel plane of heterojunction (cross geometry).

Fig. 3 shows the spectrum of the normalized PS photoconductivity at room temperature. Spectral distribution of the photocurrent present itself like a wide strip in an interval of photon energy from 1.3 to $3.2 \mathrm{eV}$. Nonequilibrium charge carriers are generated in PS. PS layer behaves as a wide-band semiconductor sensitive to the visible light.

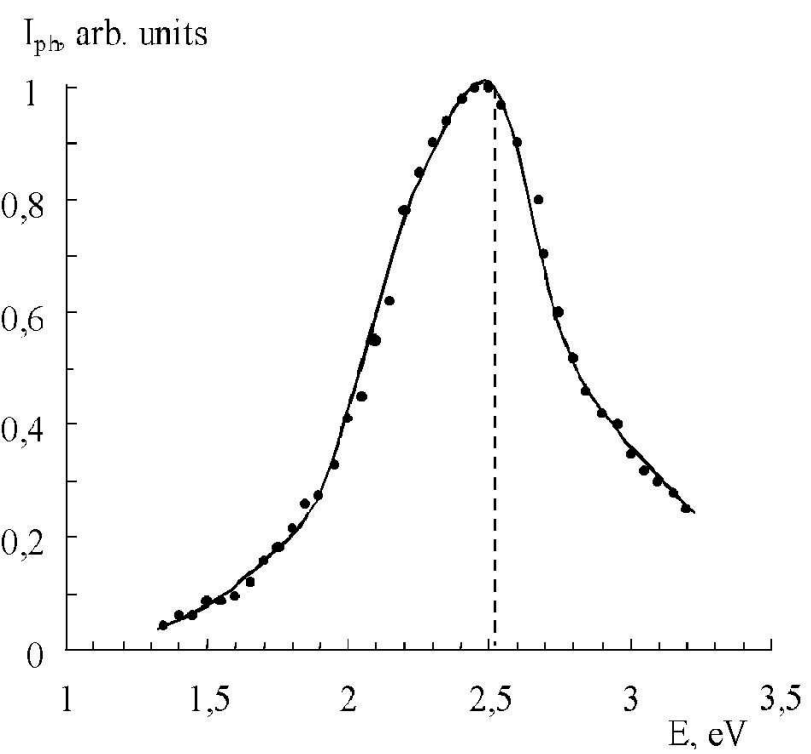

Fig. 3. Spectrum of photocurrent of porous silicon sample at room temperature.

In the method we use the circumstance, that in some of semiconductors at $h \nu=E_{g}$, the character of absorption coefficient $k$, as function of the photon energy, $h \nu$ changes. Thus the influence of surface recombination on photocurrent is taken into account.

Let the heterojunction is be limited on two parties by the sides covered by the homogeneous light flow. $d$ is the exposed front area of the sample, in a direction parallel to the heterojunction plane, is much more than the width of a layer of a volumetric charge $W$ and of diffusion lengths of the minority carriers $\left(L_{n}, L_{p}\right)$, which in turn, is much less than the heterojunction extent in the direction of light distribution $l$.

The short-circuit photocurrent in this case is connect- 
ed to an incident light flux $\Phi$ by the expression:

$$
I_{\mathrm{ph}}=q Q \Phi=q \gamma \beta \alpha \Phi
$$

where $q$ is the electronic charge; $Q$ is the quantum photosensitivity of $\mathrm{PS} / \mathrm{c}-\mathrm{Si}$ heterojunction; $\gamma$ is the factor showing which portion of the light flux will be absorbed in PS/c-Si heterojunction; $\beta$ is the quantum output of an internal photoeffect; $\alpha$ is the factor of division of $\mathrm{PS} / \rho-\mathrm{Si}$ heterojunction ( $\Phi$ being photon flow, quantum $/ \mathrm{cm}^{2} \mathrm{sec}$ ). To find dependence of $Q$ on $h \nu$, let us consider separately dependences of factors $\gamma, \beta, \alpha$ on $h \nu$.

If supposed that PS is the direct semiconductor, then lower conduction band minimum is situated in the $\Gamma$ minimum. For such a semiconductor the factor of absorption near the fundamental absorption edge grows sharply at the beginning from units up to $10^{4} \mathrm{~cm}^{-1}$, and then smoothly with an increase of $h \nu$. The smooth increase begins at $h \nu=E_{g}$. Thus the dependence of $k$ on $h \nu$ changes at $h \nu=E_{g}$. Distinction in absorption of the light by PS and crystalline silicon is that in PS the pores can play a role of waveguides. The light, got in a pore, after repeated reflections from the pore walls will penetrate far deep into PS. At the expense of it, PS absorbs light more strongly than bulk silicon. Therefore, it is promissing for creation of photodetectors on the PS base.

The factor $\gamma$, with the accounting of repeated internal reflection has the following dependence from $k, l$ and factor of reflection $R$ :

$$
\gamma=\frac{(1-R)\left(1-e^{-k l}\right)}{1-R e^{-k l}}
$$

From this formula follows that at $k<l$ factor $\gamma \sim k$ and smoothly grows at the further increase of $k$, aspiring to the limiting value $\gamma=1-R$. Therefore, the diagram of $\gamma$ versus $h \nu$ will also look like an increasing curve striving for limiting value $1-R$, which is achieved at $h \nu<E_{g}$, as at $h \nu=E_{g}, k=W^{-1}$ and $L_{n}^{-1}, L_{p}^{-1} \gg l^{-1}$.

It is possible to consider the quantum output of the internal photoeffect to be independent of $h \nu$ and equal to unity, as in direct semiconductors, the light is absorbed mainly at the expense of band-to-band transitions.

Factor of division $\alpha<1$ can show:

i) electron-hole pairs can recombinate with not achieving heterojunction, if they are formed at a distance from it, greater than the diffusion length of the minority carriers. So

$$
\alpha=\frac{W+L_{n}+L_{p}}{d}
$$

ii) electron-hole pairs can be grasped by the surface states and thus recombinate, not achieving heterojunction.

If surface recombination velocity $S$ tends toward $\infty$, factor $\alpha$ decreases with $k$ growing. And as the dependence of $k$ on $h \nu$, as mentioned above, changes the character at $h \nu=E_{g}$. So the dependence of $\alpha$ on $h \nu$ will vary too. If the speed of surface recombination $S \neq 0$ but $S \neq \infty$, the dependence of $\alpha$ on $h \nu$ will change the character at $h \nu=E_{g}$.

It is possible to establish the dependence of quantum photosensitivity $Q$ on $h \nu$. If surface recombination is not present then we have the case of $Q \sim \gamma$ since $\alpha=$ const. The definition $E_{g}$ in this case is connected with great difficulties, since at $h \nu \approx E_{g}, Q \sim(1-R)$, and $R$ very weakly depends on $h \nu$.

If the surface recombination is presented then the dependence of $Q$ on $h \nu$ has a maximum. $Q$ represents a product of two factors, one of which $\gamma$ is increasing with $h \nu$ growing, and another $\alpha$ decreases. Moreover, the photon energy, equal to $E_{g}$, is necessary on the falling down site. Character of dependence of $Q$ on $h \nu$, just as $\alpha$ on $h \nu$, at $h \nu=E_{g}$ undergoes change, namely: dependence of $Q$ on $h \nu$ should become more poor. On photon energy appropriate to the easing of the dependence of $Q$ on $h \nu$, $E_{g}$ is determined.

The results of the carried out consideration also are applicable for definition of threshold energy of $\Gamma-\Gamma$ of junction $E_{0}$ for semiconductors, at which the $\Gamma$-minimum of a conduction band is not absolute (indirect-band semiconductor). In such semiconductors the strong absorption caused by the direct band-to-band transitions is shown. To define $E_{g}$ of indirect-band semiconductors it is possible by using directly dependence of $Q$ on $h \nu$, if at $h \nu=E_{g}$, the absorption prevails at the expense of indirect band-to-band transitions. In this case $Q \sim k$, as $k$ is small $\left(<100 \mathrm{~cm}^{-1}\right)$, so $E_{g}$ can be determined on a spectrum of $Q$, in the same way as it is defined on the spectra of absorption.

The enhancing of band gap in PS is connected with quantum-size effect, in particular they consider the system of quantum wires mainly oriented at the [100] direction. Band gap for the investigated sample, as can be seen in Fig. 4, is $2.52 \mathrm{eV}$. As it is known the width of the band gap of crystal silicon is $1.1 \mathrm{eV}$. The difference in the width of band gap between silicon and PS is $1.42 \mathrm{eV}$. From the dependencies of the band gap on the diameter of quantum wires (see Fig. 4) it is possible to estimate the diameter of quantum wires. So for effective width of the band gap $2.52 \mathrm{eV}$ in the vicinity of heterojunction the diameter of quantum wires will be about $21 \AA$. The accuracy of definition of the band gap width by the advanced method is close to the accuracy of defining it on spectra of absorption.

It is known [10] that PS becomes the direct-gap semiconductor at the small cross sizes of wires $L<31 \AA$. It was shown by the calculations of band structure PS in the empirical model of strong connection in view of two nearest neighbours. The system of quantum wires focused along an axis [001] was considered, with cross section as a square, whose parties are directed on axes [110] and [1ํㅣㅇ. The surface of wires was assumed to be passivated by hydrogen. The occurrence of conduction band states near the centre of the Brillouin zone contacts to doubling of the period of a PS lattice along an axis [001] because the presence of borders breaks equivalence of edges [110] and [110]. Thus there is a downturn of the structure symmetry. 


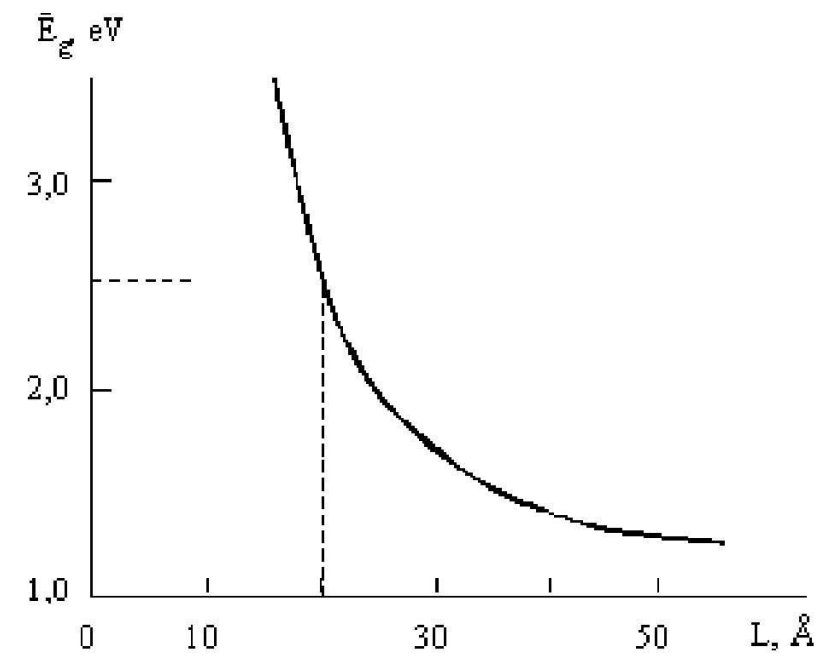

Fig. 4. The dependence of the effective band gap of PS on the cross size of a quantum wire of square section for silicon within the frameworks of isotropic model of valence band [10].

It is natural to expect, that in quantum-sized PS structure there is a significant disorder of the nanoclusters sizes. It seems, that the most suitable PS model is the model of system of quantum wires with nonuniform cross-sectional area. At the etching of PS the section of a quantum wire can vary deep into the sample, therefore, as it is visible from the photocurrent spectra, PS is a varyzone structure. From the previous conclusions it follows that the photoelectric method determines $E_{g}$ in the wide gap part of PS photoactive area.

As the photocurrent in the given structures is connected, basically, to the holes generation on the heterojunction, the measurement of photocurrent allows to define the diffusion length of the holes $\left(L_{p}\right)$. At illumination of structure PS/c-Si to which the bias is applied, the total current will have two components: a) current of carriers released at photon absorption in the field of a spatial charge. This current changes with the growth of the bias voltage as the result of depletion area thickness change; b) diffusion current of the minority carriers. For our way of illumination, along the plane of a barrier, it is possible to write down the formula for the photocurrent:

$$
I_{\mathrm{ph}}=\gamma \beta \Phi(1-R) d\left(W+L_{p}\right)
$$

where $\beta$ is accumulation factor of charge carriers; $\Phi$ is photon flow, quantum $/ \mathrm{cm}^{2} \mathrm{sec} ; R$ is refractive index of the semiconductor; $L_{p}$ is diffusion length of the holes; $d$ is length of an illuminated side of heterojunction PS/c-Si along a plane of junction.
To find the diffusion length we measured simultaneously the dependences of photocurrent and capacity of transition on the bias. On the basis of two characteristics it is possible to construct the dependence of photocurrent on the return capacity, which is shown in Fig. 5, and on it to calculate diffusion length of the minority charge carriers. Diffusion length of the minority charge carriers for various samples PS laid in limits from 0.15 to 0.65 microns.

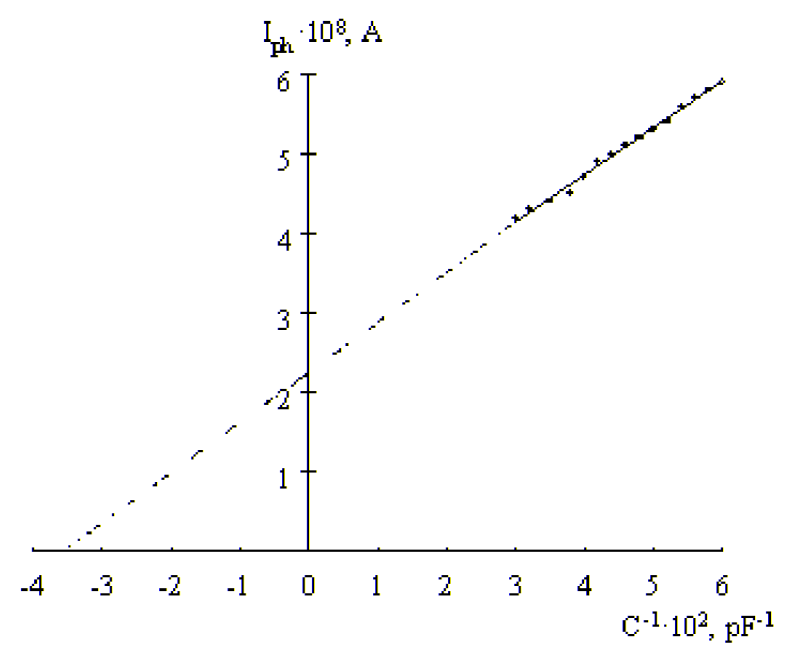

Fig. 5. Photocurrent versus PS/c-Si junction capacity at changing bias.

\section{CONCLUSIONS}

The structures $\mathrm{Al} / \mathrm{PS}-\nu$-(c-Si) are the interesting object for experimental and theoretical research of the processes of shock ionization in PS. Interpretation of this phenomenon offered in [11] in $n^{+}-\nu-n$ GaAs$\mathrm{Ga}_{1-X} \mathrm{Al}_{X}$ As heterostructures has shown that in the dark condition unlike of $p-n$ junctions only electrons injected in the area of multiplication. At the illumination of photons from the area of own absorption of PS the multiplication is initiated by electrons and holes. Therefore, it is possible to investigate separately the influence of the various factors on the magnitudes of ionization rates of electrons and holes and to determine diffusion length of the minority carriers in the given structures.
[1] A. G. Cullis, L. T. Canham, P. D. J. Calcott, J. Appl. Phys. 82, 909 (1997).

[2] D. F. Timokhov, F. P. Timokhov, V. I. Soloshenko, Works of the second international scientific-practical conference "Modern information and electronic technologies", 28-31 May 2001 (Odessa), p. 298.

[3] L. T. Canham, Phys. Lett. 57, 1051 (1990).

[4] S. M. Prokes, Phys. Lett. 63, 407 (1993). 
[5] M. Ben-Chorin, A. Kux, I. Schechter, Phys. Lett. 64, 481 (1994).

[6] D. A. Gorachev, L. V. Belakov, G. Polisky, O. M. Sresely, Fiz. Tekhn. Poluprovodn. 32, 591 (1998).

[7] A. N. Obraztsov, V. A. Caravansky, X. Okushi, X. Watanabe, Fiz. Tekhn. Poluprovodn. 32, 1001 (1998).

[8] S. A. Gevelyuk, I. K. Doycho, V. I. Soloshenko,
D. F. Timokhov, Photoelectronics iss. 11, 70 (2002).

[9] H. Shi, Y. Zheng, Y. Wang, R. Yuan, Appl. Phys. Lett. 63, 770 (1993).

[10] M. S. Bresler, I. N. Yassievich, Fiz. Tekhn. Poluprovodn. 27, 871 (1993).

[11] A. A. Ptaschenco, F. P. Timokhov, Izv. Vyssh. Uchebn. Zaved., Fiz. 6, 80 (1978).

\title{
ВИЗНАЧЕННЯ ПАРАМЕТРІВ СТРУКТУРИ ПОРУВАТОГО КРЕМНІЮ ФОТОЕЛЕКТРИЧНИМ МЕТОДОМ
}

\author{
Д. Ф. Тімохов, Ф. П. Тімохов \\ Одесъкий націоналъний університет ім. I. I. Мечникова \\ вул. Дворянсъка, 2, Одеса, UA-65026, Украӥна
}

\begin{abstract}
Подано результати дослідження електричних і фотоелектричних властивостей сендвіч-структур $\mathrm{Al} /$ поруватий кремній/монокристалічний кремній (Al/PS-(c-Si)) на основі наноструктурованого поруватого кремнію, отриманого анодизацією монокристалічних пластин. Фоточутливість структур $\mathrm{Al} / \mathrm{PS}-(\mathrm{c}-\mathrm{Si})$ визначено фотопровідністю поруватого кремнію. Розроблено фотоелектричний метод розрахунку ефективної ширини забороненої зони в околі гетеромежі PS-(c-Si). Запропоновано можливість обчислення середнього діяметра квантових ниток. Методом зворотно зміщеного фотоструму встановлено дифузійну довжину неосновних носіїв заряду в поруватому кремнії.
\end{abstract}

